\title{
Organ transplantation management in the midst of the COVID-19 outbreak: a synopsis
}

\author{
Bo-Han Zhang, Lyu-Nan Yan, Jia-Yin Yang \\ Department of Liver Surgery and Liver Transplantation Center, Organ Transplantation Center, West China Hospital of Sichuan University, \\ Chengdu 610041, China \\ Correspondence to: Jia-Yin Yang, MD, PhD. Prof., Department of Liver Surgery and Liver Transplantation Center, Organ Transplantation Center, \\ West China Hospital of Sichuan University, 37 Guoxue Lane, Wuhou District, Chengdu 610041, China. Email: docjackyang@163.com.
}

Submitted Feb 22, 2020. Accepted for publication Mar 11, 2020.

doi: 10.21037/hbsn.2020.03.16

View this article at: http://dx.doi.org/10.21037/hbsn.2020.03.16

On December 8, 2019, the first case of unexplained pneumonia was reported in China, in Wuhan, Hubei Province (1). By March 6, 2020, over 100,000 confirmed cases of coronavirus disease 2019 (COVID-19), and more than 3,400 deaths have been reported worldwide (data from National Health Commission of the People's Republic of China, Official Channels of Hong Kong, Macao and Taiwan, and World Health Organization). COVID-19, which is caused by severe acute respiratory syndrome coronavirus 2 (SARS-CoV-2), is bound to have widespread ramifications on the clinical management system, organ transplantation being a prime example. Patients on the transplant waitlist are generally in poor condition. Moreover, post-transplant patients with weak immunity stemming from the long-term and regular administration of immunosuppressants are more likely to contract the SARS-CoV-2 infection than are healthy individuals. Thus, when considering transplant patient safety, balancing organ allocation principles with epidemic prevention and control is a dilemma for transplant teams.

The COVID-19 outbreak has endangered the administration of organ transplantation. Organ transplantation teams face the following risks: (I) the probability of cross-infection among coordinators multiplies. This owes to their increased exposure due to inevitable floating workplaces and subsequent frequent contact with latent COVID-19 patients. (II) Undiagnosed COVID-19 patients lurking among donors and recipients could infect transplant recipients and medical personnel. (III) Thanks to asymptomatic infected donors and recipients, the perioperative risk of SARS-CoV-2 infection increases. This challenges the false-negative rate of realtime reverse transcriptase polymerase chain reaction tests for SARS-CoV-2 nucleic acid using samples collected from nasopharyngeal swabs (2) and the accuracy and convenience of existing means of detection. (IV) Recipients are apt to get infected postoperatively due to compromised immunity and increased hospital stays. (V) There is a shortage in the blood supply due to restricted blood donations and population mobility caused by COVID-19.

Our center has organized a multidisciplinary discussion referring to the characteristics of viral transmission and national epidemic prevention and control requirements. This will enable us to modify strategies and methods for organ transplantation in a timely manner. Donors, donor family members, recipients, recipient family members and medical personnel are the main control points. Based on pre-established protocols $(3,4)$, we have issued a modified organ transplantation management synopsis for our center in the midst of the SARS-CoV-2 pandemic. This has entailed adjusting transplantation procedure management practices including donor and recipient screening, and donor, recipient, and perioperative management (Table 1).

On January 24, 2020, the People's Government of Sichuan Province initiated a first-level response to a public health event (COVID-19). At that time, our center conducted management and work in strict accordance with the synopsis (Table 1), and received 4 cases of organ donation following citizen death. The last case included was on February 6, 2020. All of the donors were male, with an average age of 39.5 years. They were all from Sichuan Province, and there was no history of epidemiological 
Table 1 The organ transplantation management synopsis in the midst of COVID-19 prevention and control

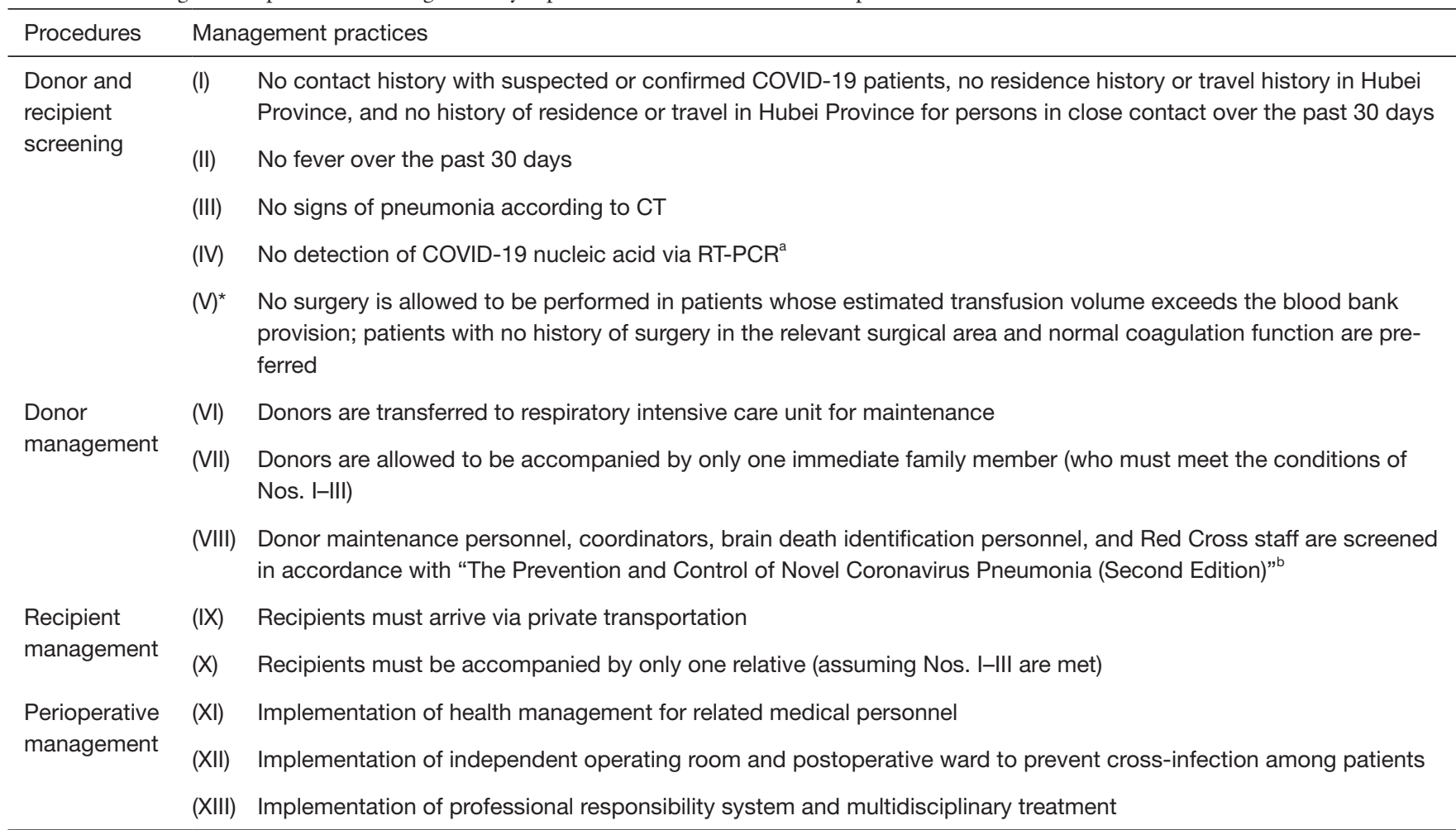

*, Only for recipients; ${ }^{a}$, two consecutive negative results (at least one day apart); ${ }^{\text {, }}$ Available online: http://www.nhc.gov.cn/jkj/ s3577/202001/c67cfe29ecf1470e8c7fc47d3b751e88.shtml. COVID-19, coronavirus disease 2019; CT, computed tomography; RT-PCR, reverse transcriptase polymerase chain reaction.

exposure. Their body temperatures had been normal over the previous 30 days, their chest CT images were normal, and they each had two consecutive negative nasopharyngeal swab results (at least one day apart). In total, 8 cases of organ transplantation were performed, including 4 cases of liver transplantation and 4 cases of kidney transplantation. There were 6 males and 2 females, with an average age of 48 years. The recipients had no history of surgery, all were from Chengdu, and none had had epidemiological exposure. Furthermore, they each had 30-day normal temperatures, negative CT findings and two consecutive negative nasopharyngeal swab results (at least one day apart). Transplantation was successful for all 8 patients, and 7 did not receive blood transfusions. All patients recovered without surgical or infection-related complications.

SARS-CoV-2's incubation period varies from 0 to 24 days, with a median of 3 days. However, SARS-CoV-2 remains contagious during the incubation period (5). To err on the side of caution, we took occult infection precautions by setting a 30-day interval before symptom onset. This action has proven both useful and prescient. Ironically, our current knowledge of transmission route and pathogenic mechanisms of SARS-CoV-2 is just the tip of the iceberg. What remains beneath the water is what should be of primary concern, rather than what little is already apparent. For example, a team led by Zhong Nan-Shan, Professor at The First Affiliated Hospital of Guangzhou Medical University, recently detected SARS-CoV-2 in the fecal samples of four newly diagnosed COVID-19 patients (4). Additionally, SARS-CoV-2 was detected in the gastrointestinal tract, saliva or urine of another four patients with positive rectal swabs. SARS-CoV-2 was also detected in the impaired site of the esophagus in a COVID-19 patient (4). The full health implications of SARS-CoV-2 may exceed our imagination in terms of both its immensity and its insidiousness.

During the raging of SARS-CoV-2, transplant recipients are at the top of the list of the susceptible population. Throughout the history of organ transplantation, there is no precedent from which to learn. This understanding has led 
to fledgling efforts to offer specific management practices to help transplant teams prepare and adapt. Even with the synopsis, plenty of fundamental work remains to be done. We believe the improvements outlined in this synopsis will safeguard the health of recipients and related medical personnel, and the resilience of our care delivery system being up against the SARS-CoV-2 pandemic. Although the epidemic in China has come under control (i.e., reduction in daily confirmed and suspected COVID-19 patients), we cannot ignore the myriad ways in which SARS-CoV-2 may undermine our clinical decision support system.

\section{Acknowledgments}

Funding: Supported by the 1.3 .5 project for disciplines of excellence, West China Hospital, Sichuan University (No. ZY2017308), the Major National Science and Technology Special Projects (No. 2017ZX10203205-005002 and 2017ZX10203205-001-004) and the National Natural Science Foundation of China (No. 81470037 and 81770653).

\section{Footnote}

Conflicts of Interest: All authors have completed the ICMJE uniform disclosure form (available at https://hbsn. amegroups.com/article/view/10.21037/hbsn.2020.03.16/coif). The authors have no conflicts of interest to declare.

Ethical Statement: The authors are accountable for all aspects of the work in ensuring that questions related to the accuracy or integrity of any part of the work are appropriately investigated and resolved.

Open Access Statement: This is an Open Access article distributed in accordance with the Creative Commons Attribution-NonCommercial-NoDerivs 4.0 International License (CC BY-NC-ND 4.0), which permits the noncommercial replication and distribution of the article with the strict proviso that no changes or edits are made and the original work is properly cited (including links to both the formal publication through the relevant DOI and the license). See: https://creativecommons.org/licenses/by-ncnd/4.0/.

\section{References}

1. World Health Organization. Disease outbreak news: Update. Novel Coronavirus - China. Geneva: World Health Organization. January 12, 2020. Available online: https://www.who.int/csr/don/12-january-2020-novelcoronavirus-china/en/

2. Xie X, Zhong Z, Zhao W, et al. Chest CT for typical 2019-nCoV pneumonia: relationship to negative RT-PCR testing. Radiology 2020. [Epub ahead of print].

3. An Update and Guidance on 2019 Novel Coronavirus (2019-nCov) for Transplant ID Clinicians. Montréal: The Transplantation Society. January 27, 2020. Available online: https://tts.org/23-tid/tid-news/657-tid-updateand-guidance-on-2019-novel-coronavirus-2019-ncov-fortransplant-id-clinicians

4. Kidney transplant and Liver transplant branches of China International Exchange and Promotion Association for Medical and Healthcare. Prevention and control strategies of organ donation and transplantation in the context of novel coronavirus pneumonia. Chin J Organ Transplant 2020;41:E001.

5. Guan WJ, Ni ZY, Hu Y, et al. Clinical characteristics of coronavirus disease 2019 in China. N Engl J Med 2020. [Epub ahead of print].
Cite this article as: Zhang BH, Yan LN, Yang JY. Organ transplantation management in the midst of the COVID-19 outbreak: a synopsis. HepatoBiliary Surg Nutr 2020;9(2):250-252. doi: $10.21037 /$ hbsn.2020.03.16 